\title{
A blueprint for an ideal corporate information centre
}

Oliver Renn, Michael Archer, Carmen Burkhardt, Jeannette Ginestet, Henning

P. Nielsen, Joanna Woodward and the P-D-R Library Affairs \& Copyright Group

Innovation is fostered by information, and so gaining and analysing information has always been a key competitive asset in any research-based company, including those in the pharmaceutical and biotechnology industries. Indeed, as an article by Agarwal and Searls noted (Can literature analysis identify innovation drivers in drug discovery? Nature Rev. Drug Discov. 8, 865-878 (2009)) $)^{1}$, the focus of innovative drug research and development (R\&D) should be guided not only by medical need and commercial potential but also by using information analysis to identify the areas in which new science is creating therapeutic opportunities.

Corporate libraries have therefore always had an indispensable function in the drug industry. Furthermore, technological advances in the past 20 years have transformed the information world, and corporate libraries have evolved into information management and knowledge centres, thus turning into innovation partners ${ }^{2-6}$.

Within companies, corporate information centres are expected to gain efficiency and to provide greater value to the multidisciplinary groups that use them, which are often distributed over several sites globally. So, such centres are constantly facing reorganization, and need to define the functions that are required to fulfil their tasks of fostering innovation, enabling access to internal and external knowledge, and integrating content into the workflow of researchers. However, there is no publication so far that describes a state-of-the-art corporate information centre. Thus, the P-D-R (Pharma Documentation Ring), an association whose members represent the scientific information departments of 21 leading international R\&Dbased pharmaceutical corporations, has developed a blueprint, which we present here, for an ideal corporate information centre (ICIC) that could be used by any company - not only in the pharmaceutical industry (see Further information for an extended version). The P-D-R has defined twelve building blocks that such an ICIC should consist of, which are described below, as well as how an ICIC should be integrated into the corporation.

\section{The 12 core elements of an ICIC}

Corporate information centres can be organized in multiple ways, but there are a set of core functions that need to be included. The twelve core elements (FIG. 1) do not need to be organizational units within an ICIC but are functions that an ICIC should include, and some elements could be merged with or embedded in other business units. However, to maximize the impact of the ICIC on the competitiveness of the company, an ICIC should integrate all of these core elements.

The twelve core elements can be grouped into four categories: information access, information research, information technology (IT) and knowledge management. FIGURE 2 summarizes and describes key features of these elements. First, the three core elements grouped under information access ensure that the content that drives

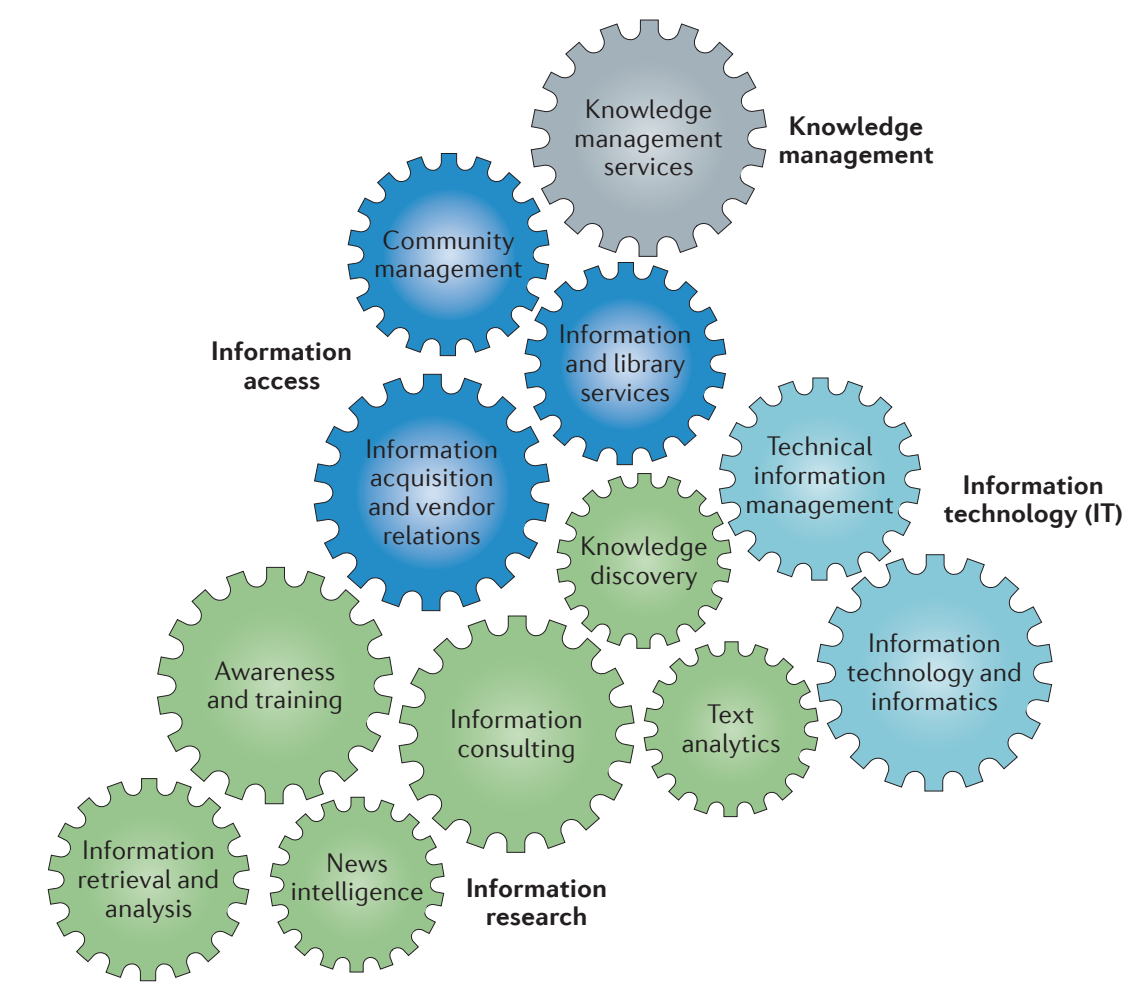

Figure 1 | The twelve core elements of an ideal corporate information centre. See FIG. 2 for a summary of the key characteristics of each element.

a corporation's $\mathrm{R} \& \mathrm{D}$ can be acquired and disseminated, which is the foundation for getting decision-making and processes right. Second, information research ensures that the money spent on information access has multiple returns, by boosting innovation and saving expenditure in R\&D. This is done by reaching out to researchers as well as by providing individual consultancy and highly customized information services. Third, an ICIC needs a state-of-the-art information architecture to support its services and allow integration into the workflow of users. Last, knowledge management should be an attitude that characterizes the ICIC overall, and does not necessarily need to be an organizational unit, but it has been included in the twelve core elements.

\section{Reporting line of the ICIC}

Information centres are found in various positions in the company structure. At present, the majority $(\sim 60 \%)$ of information centres in the member companies of the P-D-R report into the R\&D function. The general rationale for this is that many of the users are in $R \& D$ and they appreciate that success depends on access to cutting-edge information services. However, in companies in which an information centre provides services for the entire 
Core element

\section{Information access}

1 Information acquisition and vendor relations: leverages the corporation's buying powe at equitable prices, and ensures effective

2 Information and library services: ensures that the company benefits from having access to the content available and that legitimate copies of the material are used

3 Community management: in order to ensure that it continues to be adequately funded, a marketing plan is essential for focusing on the benefits to the corporation to provide consistent information quality processes and compliance continue to show the value of the $\mathrm{ICIC}$ and

Key characteristics of core element

Skills and experience

- Procures and licenses external published information resources

- Conducts ongoing contract and strategic vendor relationship

management, developing long-term partnerships

- Conducts ongoing content and vendor evaluations

- Identifies and prioritizes customer needs through governance groups

\section{- Provides document delivery services}

- Ensures copyright compliance in collaboration with legal professionals

- Responds to 'ask a librarian' reference questions

- Collects client feedback and usage statistics to inform renewal decisions

- May provide other services such as literature surveillance, product

literature database services and article translations

\section{- Conducts stakeholder management}

- Owns the communication strategy through the year, focusing on specific resources

- Provides branding and marketing of information resources and services

- Liaises with business partners to cross-charge budget for specialist content

\section{Information research}

4 Awareness and training: information, particularly scientific information, and the subsequent knowledge derived from published information, is the vital resource of all knowledge workers

5 Information consulting services: information specialists can assist knowledge workers to navigate the increasing number and functionality of databases on the market

6 Information retrieval and analysis: crucial when a decision requires the support of all relevant published literature in the field to ensure competitive advantage and help filter literature to obtain the most relevant information

7 News intelligence business: crucial need for a function that provides relevant business and scientific news targeted towards specific communities in a corporation

8 Text analytics: provides services using data mining tools that allow knowledge discovery within unstructured content

9 Knowledge discovery: owing to the exponential growth of structured and unstructured information, knowledge inside data silos must be made available

\section{Information technology (IT)}

10 Technical information management: the company's ability to manage and use information effectively is a key factor in determining how well a company can deal with complexity

11 IT and informatics: the $\mathrm{ICIC}$ relies on the smooth running of its information services and the availability of published content for its clients

\section{Knowledge management}

12 Knowledge management services: the success of a pharmaceutical company is based on knowledge, on druggable targets, on how to develop and optimize a compound for initial clinical trials, and on how to conduct the clinical development until submission
- Ensures that any employee who can benefit from available internal and licensed information resources and tools is aware of what is available

- Offers focused support to customers with particular scientific issues to solve based on specialist knowledge and familiarity with all licensed and free information resources and solutions

- Provides advice on utility of information resources and tools

\section{- Supports the decision-making process for patent professionals and RED} scientists, as well as for medical and business analyses and development

- Supports other areas in which particular knowledge about where and how to retrieve requested information is required

\section{- Responsible for the surveillance, evaluation and dissemination of news} in media relating to the corporation, its competitors, its business areas and other issues representing threats or opportunities

- Evaluates news aggregators as possible solutions

- Provides a framework for text analytics solutions to scientific questions

- Provides a working knowledge of current tools available, both commercial and open-source, including their limitations, as well as how queries and indexed annotated content are subsequently used for analyses

- Develops ontologies and taxonomies to use with internal and external content

- Provides a framework for data mining, including preparation of data as well as analysis of results

- Delivers tools that optimize database access, such as visualization tools

- Coordinates on alliances and with external collaborations, especially in a pre-competitive environment

\section{- Provides a technology framework for information management in} collaboration with IT, including processes and workflows for data and information handling

- Provides enterprise definitions and values for taxonomies and ontologies to facilitate the integration of data from internal and external sources

- Designs or selects software to provide information management technology solutions: for example, full-text linking services services: for example, e-library portals, document delivery systems and linking services

- Drives technology improvements to enhance those services
- Supports the IT solutions required to operate the ICIC's products and
Librarians; specialists; information scientists; vendor management

\section{Librarians; copyright}

law; customer relationship management; service ownership; data analysts; information scientists

\section{Librarians;}

information

scientists;

communication

specialists procurement
Librarians;

information

scientists; training

Information scientists

Information scientists

\section{Librarians;}

information scientists; communication specialists

Bioinformaticians; information scientists

Data analysts; information architects; data visualization and analysis expertise

\section{Developers;}

information

architects; technical specialists

\section{Library systems}

specialists; IT support

Technical and cultural working knowledge of developments in pharma knowledge sources
Figure 2 | The twelve core elements of an ideal corporate information centre. The elements are shown in a pictorial form in FIG. 1 and are

- Defined as a concept rather than a function, knowledge
management services involve consolidating disparate sources of
knowledge
- Establishes the total knowledge bank of the organization, including
tacit knowledge
- Fosters knowledge sharing and exchange

Defined as a concept rather than a function, knowledge knowledge

- Establishes the total knowledge bank of the organization, including colour-coded accordingly here. ICIC, ideal corporate information centre; RED, research and development. 
company (for example, also including sales and marketing), prioritizing needs and budget demands becomes an issue.

About $20 \%$ of information centres report into the IT function. IT serves the whole company and has become a vital part of the infrastructure (similarly to the information centre); however, this is where the similarity ends. The disadvantage of reporting into IT is that technology takes over and the focus tends to be shifted towards hardware and software management, rather than on catalysing innovation through facilitating information dissemination and analysis.

The corporate-wide nature of information services suggests that there could be advantages in having a reporting line with other corporate services, as do $20 \%$ of information centres in the P-D-R. The issue here is that although these are serving the whole company, they may well be seen as an overhead, with little understanding of their value.

In our view, the ideal reporting line for a corporate information centre would be to someone at board level who understands all aspects of information management, but otherwise into the part of the organization in which information as a key competitive asset is best understood, which is most likely to be R\&D.

\section{How can ICIC budgets be set?}

All departments need information in their work processes, as much as they need IT services and a basic workplace, and so in general the ideal way of budgeting is to take the cost centrally with no back- or cross-charging at the level of individuals or teams. This ensures that information will not be missed because it is too expensive. However, it is equally important to visualize its cost, as the impression that information is free is widespread.

Sharing or back-charging of costs across the corporation is also often done on the basis of employee numbers, and it makes sense if combined with usage, but adds to the administration costs.

Another way of setting an information budget would be as a percentage of total spending, or of spending on R\&D. However, in a cross-organizational CIC the priorities would become a problem if the $\mathrm{R} \& \mathrm{D}$ budget is going to be cut, because this would result in reduced information resources for other functions.

The opposite option to having a centrally funded resource is to organize for information suppliers to charge the departments directly on a per-use basis or a full charge-back model. This has the disadvantage of placing a high administrative burden on the information centre while shifting the focus of negotiations away from vendors of information and analysis tools towards internal bargaining between users and the centre.

So, in our view, having a fixed ICIC budget derived from general funding by all user groups from a high level, based on a clear information strategy and a thorough audit process, is the most effective.

\section{The question of physical space}

With the disappearance of the classical library, there is a declining need for physical space to store information. Nevertheless, there still needs to be a space that hosts the ICIC staff and that preferably has meeting rooms and presentation rooms that could be used for raising awareness, training activities and other interactions with users.

\section{Benefits of an ICIC}

A quote attributed to Harvard University chemistry professor Frank Westheimer "A month in the laboratory can often save an hour in the library" - is even more pertinent in this era of the virtual library. Pharmaceutical R\&D depends on access to information such as the published literature. So how do we put a value to it and decide on a budget for it? There have been several attempts to calculate return on investment, mostly by publishers ${ }^{7-11}$. Another way of considering the value is to estimate the cost in the case of information not being available: for example, if a company misses a paper reporting toxic effects, which would - if known result in a project being halted or changed. The cost of not getting or applying information could be millions of dollars. Every company manages information at some level, but the companies that outperform the competition are likely to be those that have optimized their information management capabilities.
Oliver Renn (formerly at Boehringer Ingelheim) is at Adalbert-Stifter-Straße 16, 79102 Freiburg, Germany.

Michael Archer (formerly at AstraZeneca) is at Swets Information Services, Abingdon Business Park, Abingdon, Oxfordshire OX14 1UQ, UK. Carmen Burkhardt is at Novartis, CH-4056 Basel, Switzerland.

Jeannette Ginestet has recently retired from Sanofi-aventis Montpellier, France. Henning P. Nielsen is at Novo Nordisk, DK-2880 Bagsvcerd, Denmark.

Joanna Woodward is at Pfizer, Eastern Point Road, Groton, Connecticut 06340, USA.

Correspondence to O.R. e-mail: olrenn@aol.com doi: 10.1038/nrd2973-c1

1. Agarwal, P. \& Searls, D. B. Can literature analysis identify innovation drivers in drug discovery? Nature Rev. Drug Discov. 8, 865-878 (2009).

2. Lindberg, D. A. B. \& Humphreys, B. L. 2015 - the future of medical libraries. N. Engl. J. Med. 352 , 1067-1070 (2005)

3. Simon, C. An examination of best practices and benchmarking in corporate libraries. J. Manag. Dev. 30, 134-141 (2011).

4. Lustig, J. \& Wilson, K. Executive summary Pharmaceutical Information Services 2008: Benchmarking and Best Practices among the Largest Players in the Global Pharmaceutical Industry. Outsell Inc. website [online], http://www.outsellinc.com/store/ products/785-executive-summary---pharmaceuticalinformation-services-2008-benchmarks-and-bestpractices-among-the-largest-players-in-the-globalpharmaceutical-industry (June 2008).

5. Matarazzo, J. M. \& Pearlstein, T. A review of research related to management of corporate libraries. Adv. Librarianship 31, 93-114 (2008).

6. Nielsen, H. P. \& Vogt, S. O. What pharmaceutical libraries really want. Learned Publishing 23, 53-58 (2010).

7. Akel, M. \& Associates. The role of paid R\&D information tools in helping achieve C-suite objectives. Elsevier for Industry website [online], www.elsevierforindustry.com/resource_center/pdf/ akel2010.pdf (2010).

8. Hydock, J., McShea, J. ¿ Ohri, M. Establishing Value and ROI: investing in STM e-journals and e-books. Springer website [online], http://www.springer.com librarians/for $+r+\% 26+d$ ? SGWID $=1-40475-12$ librarians/for $+r+9$

9. He, L., Chaudhuri, B. \& Juterbock, D. Creating and measuring value in a corporate library. Information Outlook 13, 13-16 (2009).

10. Botha, E., Erasmus, R. \& Van Deventer, M. Evaluating the impact of a special library and information science. J. Librarianship Information Sci. 41, 108-123 (2009)

11. Hendriks, B. $\&$ Wooler, I. Establishing the return on investment for information and knowledge services: a practical approach to show added value for information and knowledge centres, corporate libraries and documentation centres. Bus. Inf. Rev. 23, 13-25 (2006).

Competing interests statement

The authors declare no competing financial interests.

FURTHER INFORMATION

P-D-R Pharma Documentation Ring - P-D-R related publications: www.p-d-r.com/content/publications

ALL LINKS ARE ACTIVE IN THE ONLINE PDF 